\title{
Self-Supporting Thin Yttria-Stabilised Zirconia Electrolytes for Solid Oxide Fuel Cells Prepared by Laser Machining
}

\author{
A. Larrea, ${ }^{*, z}$ D. Sola, ${ }^{a}$ M. A. Laguna-Bercero, J. I. Peña, R. I. Merino, and V. M. Orera
}

Instituto de Ciencia de Materiales de Aragón, CSIC- U. Zaragoza, E-50.018 Zaragoza, Spain

A novel procedure to make self-supporting thin yttria-stabilised zirconia (YSZ) membranes by laser machining is shown. We have used a galvanometric controlled laser beam to machine the surface of a conventional sintered YSZ plate and achieved thin areas up to $10 \mu \mathrm{m}$ thick, but also maintaining thicker support beams to ensure the structural strength of the membrane. The outer areas of the plate are left unaltered to facilitate the sealing of the cell. This kind of thin membrane is ideal for preparing electrolytesupported Solid Oxide Fuel Cells (SOFC) operating at intermediate temperatures. The membranes have been characterized by optical profilometry, Raman Spectroscopy and Electrochemical Impedance Spectroscopy. The YSZ properties, except those derived from membrane thinning, remain unaltered by processing. Using the laser machined YSZ electrolyte a conventional electrolyte supported YSZ-Ni/YSZ/LSM-YSZ planar single cell with average electrolyte thickness of less than $50 \mu \mathrm{m}$ has been fabricated and characterized. Performance of the cell is improved as a result of the thinning process.

(c) 2011 The Electrochemical Society. [DOI: 10.1149/1.3619759] All rights reserved.

Manuscript submitted June 3, 2011; revised manuscript received July 7, 2011. Published August 2, 2011. This was Paper 771 presented at the Montreal, QC, Canada, Meeting of the Society, May 1-6, 2011.

The Solid Oxide Fuel Cell (SOFC) is one of the key devices for the transformation from the present fossil fuel based economy to a clean economy with zero emission energy use. The core of the SOFC is a solid electrolyte, an ionic conductor at high temperatures. At present, yttria-stabilised zirconia (YSZ) is still the most used electrolyte because of its unrivalled mechanical properties, chemical stability and high degree of knowledge achieved in this material. ${ }^{1}$ As a first approach, the solid electrolyte behavior determines the cell performance and operation temperature. In this way, the Area Specific Resistance (ASR) of the electrolyte, defined as the ratio between the voltage drop in the electrolyte and the current density, is one of the main parameters of a SOFC. It is usually considered that this value has to be lower than $\sim 0.15 \Omega \cdot \mathrm{cm}^{2}$ to get a cell with good performances. ${ }^{2}$ The resistance of a conductor follows the relationship

$$
R=\frac{l}{S \cdot \sigma}
$$

The conductivity being $\sigma, l$ the thickness and $S$ the surface of the material. The conductivity of YSZ is a function of the temperature according to an Arrhenius type law

$$
\sigma(T)=\frac{A}{T} e^{-\frac{E_{a}}{k T}}
$$

where $T$ is the temperature, $A$ the pre-exponential factor, $E_{a}$ the activation energy and $k$ the Boltzmann constant. Since YSZ is a relatively poor electric conductor with $\mathrm{E}_{\mathrm{a}} \approx 1.1 \mathrm{eV}$ and $\sigma\left(1000^{\circ} \mathrm{C}\right)$ $\approx 0.1 \Omega^{-1} \mathrm{~cm}^{-1}$, (Ref. 3) the direct way to obtain low cell resistance is to prepare the electrolyte as a thin film and/or to operate the cell at high temperatures to get high enough ionic conductivity.

Thin electrolytes can be deposited using different techniques such as tape casting, dip coating, spray-painting, etc. over one of the electrodes (either the cathode or the anode) that operate as structural support for the cell. The main advantage of this electrode-supported cell configuration is that very thin electrolytes can be used (usually $10-30 \mu \mathrm{m})$ and thus low resistance values are obtained for the most common electrolytes at intermediate temperatures (typically $\left.750-850^{\circ} \mathrm{C}\right){ }^{4}$ Lowering the operation temperature also enables the use of cheaper materials for the stacks (interconnectors, manifolds, etc) and, in general, increases the long-term stability of the cell. Although electrode supported cells are now the most prevalent type of SOFCs, they are not problem free. For instance, electrode-

\footnotetext{
* Electrochemical Society Active Member.

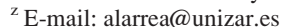

${ }^{a}$ Present address: Centro de Física de Materiales, Universidad del País VascoCSIC, E-48.013 Bilbao, Spain
}

supported cells usually have gas transport limitations due to the electrode thickness needed to act as structural support for the whole cell. In addition, anode supported cells present redox stability problems that can lead to the degradation of the cell performance and eventually to the fracture of the cell. Interconnectors or other metallic parts can also be used as support material, but in this case ceramic processing becomes more complex. The thin electrolyte layer has to be dense and gas-tight, which is difficult in this case as it has to be deposited over a porous electrode that will contract during sintering. It is essential to carefully adjust the thermal processing of the cell to co-sinter all ceramic parts together and obtain the final desired microstructure. In fact this is probably the main challenge in current SOFC technology. Moreover, most of the materials used as cathodes can react during sintering with the electrolyte forming insulating compounds at the interface. These problems are usually solved by adding buffer layers between the different parts of the cell, and thus increasing the complexity and price of the device.

Alternatively to electrode-supported configurations, electrolytesupported SOFC are preferred in terms of robustness and resistance to redox cycles of the cell. In this case thin electrodes $(10-30 \mu \mathrm{m})$ are deposited over a previously sintered electrolyte. Since the electrolyte is here the structural component of the cell, gas transport in the cathode is not a serious concern and crack formation in the anode by re-oxidation do not seriously compromise the cell structural integrity. One of the main advantages of electrolyte-supported cells is that the electrolyte is the only dense and gas-tight ceramic layer in the cell. So, as it usually requires the highest sintering temperatures, the other ceramic layers can be sintered at lower temperatures. This minimizes the reactivity problems between the different compounds during sintering and also favors the achievement of the optimum porosity for gas transport in the electrodes. However, the main inconvenience of this design is that electrolyte supported cells are prepared over 100-300 $\mu$ m thick electrolytes and, as a consequence, they are designed to operate at high temperatures, typically $\sim 1000^{\circ} \mathrm{C}$ for YSZ electrolytes. Higher temperatures are not usually used due to degradation problems. ${ }^{5}$

The ideal situation would be the fabrication of electrolytes thinner than $30-50 \mu \mathrm{m}$, but also presenting good mechanical properties in order to support the rest of the ceramic layers and to favor the sealing with interconnectors. In this way some authors have prepared thin and freestanding YSZ and Gadolinia Doped Ceria (GDC) membranes using micro-machining techniques from semiconductor technology. ${ }^{6,7}$ According to this procedure, using electron beam evaporation or magnetron sputtering techniques, a very thin ionic conductor membrane is deposited over a silicon wafer that has been previously nitrided, masked and etched. Then, selective silicon nitride removal leads to freestanding electrolyte membranes with thickness lower than $1 \mu \mathrm{m}$ and side dimensions as large as $1 \mathrm{~mm}$. Using the same technology Berkowitz and co-workers have also 
prepared $50 \times 50 \mu \mathrm{m}$ YSZ membranes over $\mathrm{LaAlO}_{3}$ substrates. ${ }^{8}$ However, this procedure has the inconvenience of the different Thermal Expansion Coefficients (TEC) between membrane and support that finally leads to the fracture of the thin membrane after some temperature cycles. The company NexTech Materials has developed another approach: they have deposited a $50 \mu \mathrm{m}$ electrolyte layer over a perforated zirconia mesh. ${ }^{9}$ In this case the thickness of the membrane is conditioned by the size of the mesh aperture and the deposition technique. On the other hand several methods have been reported for the production of free-standing ultrathin ceramic foils that can be later deposited onto different ceramic or metallic substrates. ${ }^{10}$

A different alternative is presented is this paper. We have developed a new method to produce self-supported thin ionic conducting membranes by laser machining of YSZ plates. ${ }^{11}$ A galvanometric controlled pulsed $\mathrm{Nd}: \mathrm{YVO}_{4}$ laser was used to efficiently machine honeycomb patterns in a conventional $150 \mu \mathrm{m}$ thick YSZ plate getting thin areas up to $10 \mu \mathrm{m}$ thick, but also maintaining thicker support beams of the same original material to ensure the structural strength of the membrane. Thus the mechanical strength of the membrane can be tailored according to the requirements of the cell manufacture. Moreover, laser machining is a relatively low cost technology with the advantage of the high precision and excellent surface quality achieved and it has been previously used to drill $\mathrm{NiO} / \mathrm{YSZ}$ ceramics to fabricate porous Ni-YSZ cermets. ${ }^{12,13}$ In low thermal conduction materials and under laser ablation conditions the heat-affected zone around the processed areas is small enough to avoid cracking, phase changes or deterioration of the material performance. In the present case the outer areas were left unaltered to facilitate the sealing of the cell. As the final piece is obtained from an original YSZ plate, all parts present the same TEC and do not show problems of cracking due to thermal cycles. The preparation method can be applied to different electrolytes.

In order to prove the concept, electrolyte supported YSZ-Ni/YSZ/ LSM-YSZ planar SOFCs have been fabricated using the honeycomb laser-machined electrolytes. The electrochemical response of the cells, as determined by the $j-\mathrm{V}$ curves, was compared with that of unprocessed cells fabricated in the same way but from non-machined electrolyte. The results demonstrate the decrease in the ASR and the better performance on the cells built with machined electrolytes.

\section{Experimental Details}

Laser machining was performed on commercial 8YSZ $\left(\mathrm{ZrO}_{2}\right.$ doped with $\left.8 \mathrm{~mol} \% \mathrm{Y}_{2} \mathrm{O}_{3}\right) 50 \times 50 \mathrm{~mm}$ plates form Kerafol $\mathrm{GmbH}$ (Stegenthumbach 4-6, D-92676 Eschenbach, Germany). The original thickness of the plates was $150 \pm 15 \mu \mathrm{m}$ and the ionic conductivity $\sigma>10 \mathrm{~S} / \mathrm{m}$ at $850^{\circ} \mathrm{C}$. To machine the plates we used a Q-switch diode pumped Nd: $\mathrm{YVO}_{4}$ laser (Model TruMark 6230, Trumpf, Grüsch, Switzerland) with $7 \mathrm{~W}$ of average power. The beam was $\mathrm{TEM}_{00}$ type, the quality factor $\mathrm{M}^{2}<1.2$ and the wavelength $\lambda=532 \mathrm{~nm}$. The laser was equipped with a computer-controlled system of galvanometric mirrors to deflect the beam and scan the surface of the plate according to the pattern defined by the Computer Assisted Design (CAD) software. An optical lens with a focal distance of $100 \mathrm{~mm}$ placed at the output of the scanner allows a minimum size of the laser spot of 12 $\mu \mathrm{m}$. The optical absorption spectrum of the original YSZ plate was evaluated from the in-line transmittance of a $150 \mu \mathrm{m}$ thick unprocessed plate, measured using a VARIAN 500 UV-VIS-NIR optical spectrophotometer. The size of the machined areas (depth and lateral dimensions) was determined by optical profilometry using a confocal optical microscope (Model Sensofar PL $\mu 2300$, Nikon Instruments Europe B.V. Amstelveen, The Netherlands). Raman dispersion measurements were performed under a backscattering geometry, using an optical microprobe spectrometer (Model XY, DILOR, Lille, France) with a diode array multichannel detector to locally observe any phase change in the YSZ structure. An $\mathrm{Ar}^{+}$laser with wavelength $\lambda=514.0$ $\mathrm{nm}$ and $100 \mathrm{~mW}$ power was used for these experiments. Electrochemical Impedance Spectroscopy (EIS) was carried out using a Solartron analyser model SI1260 (Schlumberger Technologies Hampshire, England). In the EIS experiments the electrodes were prepared applying platinum paste (type 6082A, Engelhard-CLAL, Paris, France) on both surfaces of the plates followed by calcination at $850^{\circ} \mathrm{C}$. Scanning Electron Microscope images were obtained using a Jeol 6400 microscope (Jeol, Tokyo, Japan). For the $j$-V measurements terpineol-based slurries (Sigma-Aldrich) of NiO-YSZ (50/50 wt \% from Alfa Aesar and Tosoh respectively) and $\left(\mathrm{La}_{0.8} \mathrm{Sr}_{0.2}\right)_{0.98} \mathrm{MnO}_{3}$-YSZ (50/50 wt \% LSM-YSZ from FuelCell Materials) were deposited by brush-painting on both sides of the YSZ plates. NiO-YSZ electrode ( $\sim 30 \mu$ m thickness) was sintered at $1350^{\circ} \mathrm{C}$ for $1.5 \mathrm{~h}$ and then LSM-YSZ $(\sim 30 \mu \mathrm{m}$ thickness) was sintered at $1150^{\circ} \mathrm{C}$ for $1.5 \mathrm{~h}$. Samples were finally sealed into an alumina tube using Omegabond ${ }^{\circledR} 700$ high temperature sealant (Omega Engineering Inc., Stanford, US). The measurements were performed using four Pt wires to measure voltage and current. A $\mathrm{Pt}$ mesh was attached to the electrodes for current collection using $\mathrm{NiO}$ and LSM pastes for the anode and cathode respectively. Nickel oxide was reduced to metallic nickel during the heating process at $800^{\circ} \mathrm{C}$ under pure hydrogen saturated with deionized water at room temperature $\left(\sim 3 \% \mathrm{H}_{2} \mathrm{O}\right)$. $j$-V measurements were recorded using a VSP Potentiostat/Galvanostat (Princeton Applied Research, Oak Ridge, US) at temperatures between 750 and $850^{\circ} \mathrm{C}$ using $3 \% \mathrm{H}_{2} \mathrm{O} / 97 \% \mathrm{H}_{2}$ at the anode $(\mathrm{Q}=50 \mathrm{ml} / \mathrm{min})$ and synthetic air at the cathode site $(\mathrm{Q}=100 \mathrm{ml} / \mathrm{min})$.

\section{Results and Discussion}

Laser machining of the electrolyte.-The thin and self-supporting YSZ membranes were prepared from conventional $150 \mu \mathrm{m}$ thick YSZ plates by laser machining. The laser processing was carried out using a pulse frequency of $15 \mathrm{kHz}$ and pulses of $0.24 \mathrm{~mJ}$ of energy with pulse length of $7.5 \mathrm{~ns}$. The unprocessed plates were placed 2 $\mathrm{mm}$ under the focal plain to attain maximum efficiency. ${ }^{14}$ The parallelism between the laser head and the plate was ensured using a precision lever. The depth of material removal was controlled varying the number of scans hitting the different areas.

Two critical lengths are of importance in the laser process. The optical absorption length, $L_{\alpha}$, defined as the inverse of the optical absorption coefficient $\alpha$, and the thermal diffusion length, $L_{t h}$, proportional to the square root of the thermal diffusivity $\mathrm{D}$ and pulse width $\tau$ and given by

$$
L_{t h}=2 \sqrt{D \tau}
$$

Using the value of $\mathrm{D} \approx 0.0063 \mathrm{~cm}^{2} / \mathrm{s}$ (Ref. 15 ) we obtain a typical thermal diffusion length in YSZ of about $0.07 \mu \mathrm{m}$, much smaller than the optical penetration length. The absorption spectrum of the

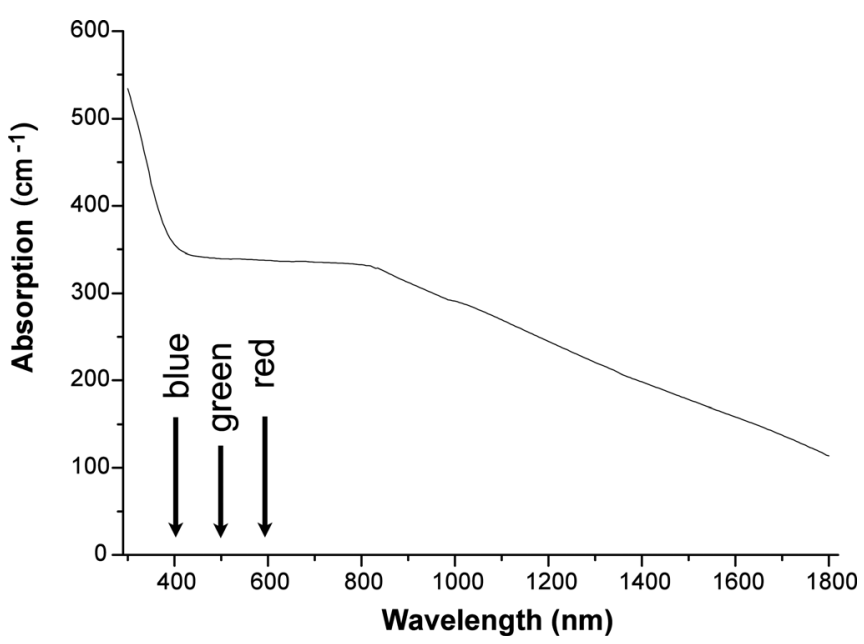

Figure 1. Optical absorption spectrum of the YSZ plate. 


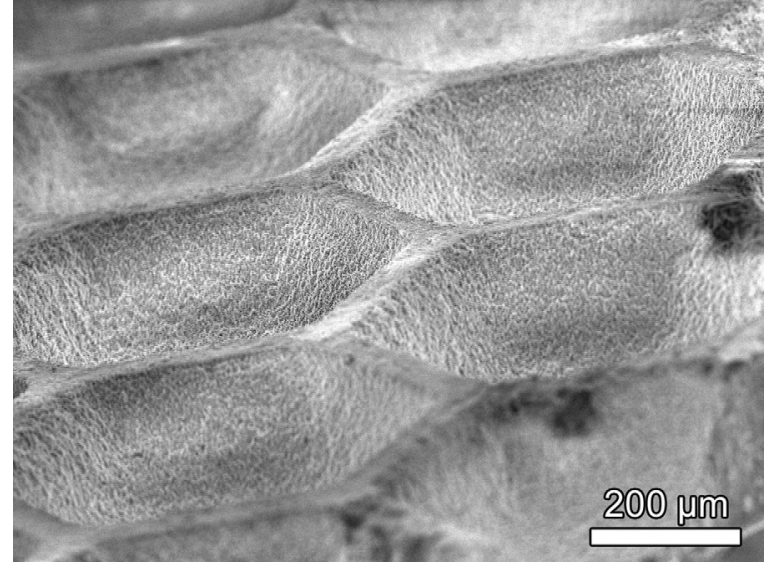

Figure 2. SEM image of a hexagonal patterned machined plate.

YSZ material is given in Fig. 1. The absorption increases in the blue region of the visible spectrum making the absorption of the laser light more efficient for shorter wavelengths. At $\lambda=532 \mathrm{~nm}$ the optical length is about $24.6 \mu \mathrm{m}$. With these irradiation conditions the laser beam, of $136 \mu \mathrm{m}$ diameter, scanned the surface plate removing material according to a photo-thermal laser ablation process. ${ }^{15}$ This process consists of the absorption of laser energy and subsequent evaporation of the material, leaving the contiguous unirradiated zones as well as the zones that are underneath of the irradiated ones essentially unaltered.

In Fig. 2, a SEM image of a hexagonal patterned plate is shown. The time consumption to machine each hexagon was $560 \mathrm{~ms}$, as the hexagon size is $1=200 \mu \mathrm{m}$ and the depth about $120 \mu \mathrm{m}$, the surface and volume processing rates being $0.027 \mathrm{~mm}^{2} / \mathrm{s}$ and $0.2 \mathrm{~mm}^{3} / \mathrm{s}$ respectively. The removal rate was of $1785 \mu \mathrm{m}^{3}$ per pulse, typical of the thermal laser-material interaction process previously
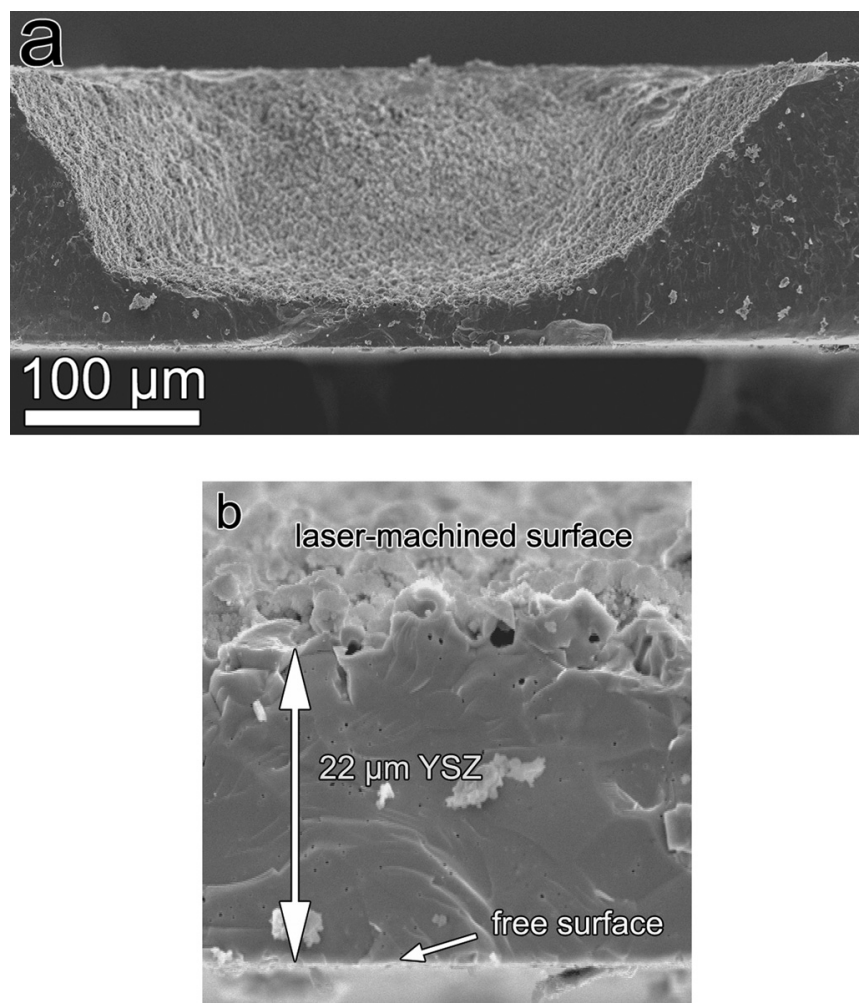

Figure 3. SEM image of the fracture cross-section of the machined plate. a) Overall view of an excavated hexagon. b) Detail of the bottom. described. ${ }^{12}$ However, these processing rates were obtained in laboratory conditions using several scans with moderate laser pulse energy to better control the removed depth. For industrial scalability these processing rates could be improved by at least 2 or 3 orders of magnitude.

To maintain high structural robustness of the membrane, each hexagon is separated from the adjacent ones by $100 \mu \mathrm{m}$, maintaining an unprocessed area acting as structural support. In Fig. 3, a transverse cross-section of the machined plate is shown. The thickness at the hexagon bottom is about $20 \mu \mathrm{m}$. In this picture it can be observed that some debris, YSZ nanometric powder, resulting from the laser ablative process covers the machined area. Although the plate thickness at the hexagon bottom is about $20 \mu \mathrm{m}$, as the walls of the machined area are not really perpendicular, the average thickness of the plate estimated from the SEM pictures is about 50-55 $\mu \mathrm{m}$. No cracks or defects produced by the laser machining were observed in any plate, even in very thin areas up to $10 \mu \mathrm{m}$ thick.

The depth of the machined area has also been estimated from optical profilometry. In Fig. 4a a 2D representation of the height of the machined plate is shown, whereas in Fig. $4 \mathrm{~b}$ the depth profile along the line indicated in Fig. 4a is represented. The depth of the machined area is about $128 \mu \mathrm{m}$, so the thickness at the bottom is about $22 \mu \mathrm{m}$. The measured size of the hexagons is $230 \mu \mathrm{m}$, larger than the size defined by the laser plot because of the laser spot width. From the optical profilometry the average thickness of the hexagons is $\sim 46 \mu \mathrm{m}$; and including the non-machined areas the average thickness of the machined plate is $\sim 59 \mu \mathrm{m}$.

Physical characterization of the electrolyte-To verify if laser ablation induces any structural phase transformation in the YSZ phase, Raman spectroscopic experiments were carried out in the
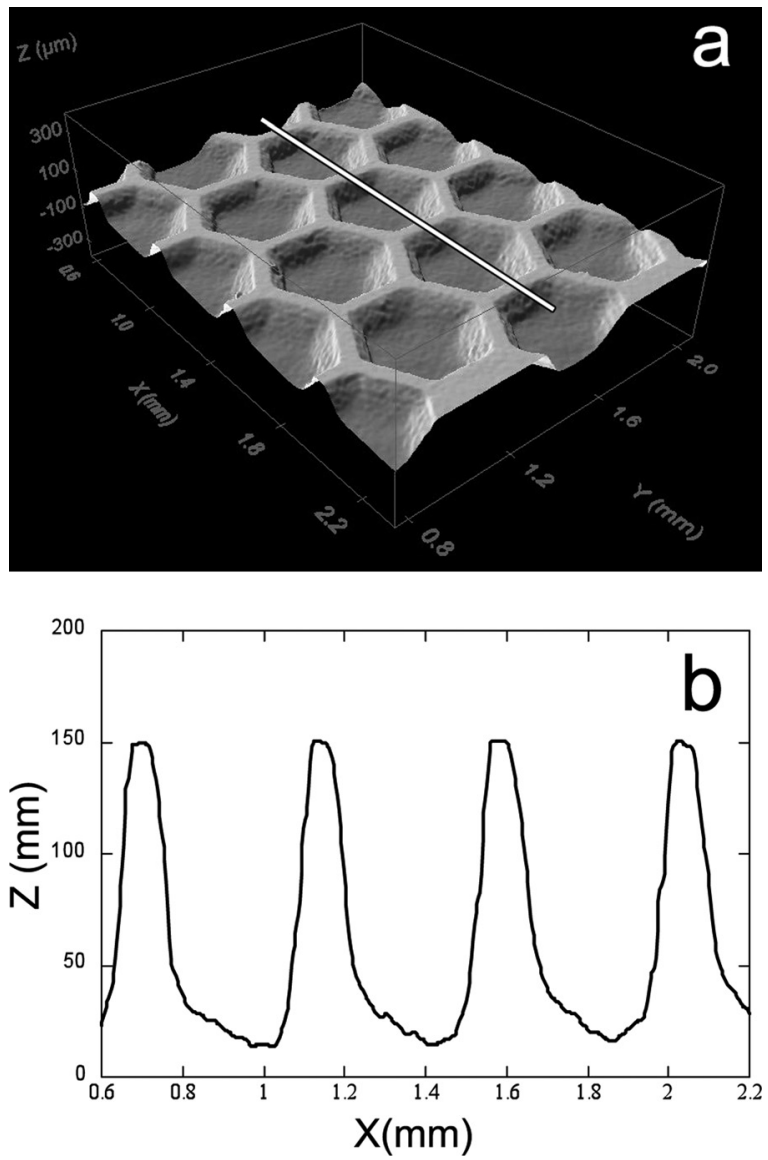

Figure 4. Optical profilometry of the machined area. a) 2D representation of the height of the plate. b) Height profile along the line indicated in 4a. 


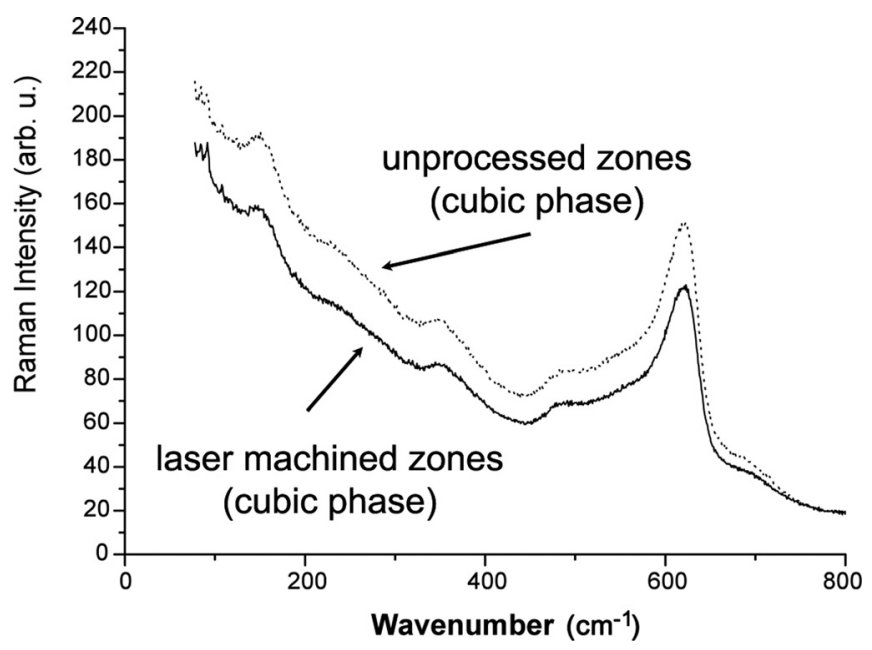

Figure 5. Raman spectra of the unprocessed (dot) and laser machined areas (black line).

walls of the processed areas looking for any YSZ phase transformation induced by the laser treatment. Phase transformation from cubic to tetragonal phase is usually associated with local ordering of the oxygen vacancies and would lead to a decrease of the ionic conductivity of the electrolyte. ${ }^{16}$ In fact Raman spectroscopy is an appropriate technique to determine the polymorphs of zirconia because of its sensitivity to small changes in bond lengths and angles as well as to symmetry changes. ${ }^{17}$ It has been intensively used to distinguish between the different tetragonal phases and between monoclinic, tetragonal and cubic phases in YSZ. ${ }^{18,19}$ This is of importance not only for the deterioration in the ceramic mechanical strength associated with possible phase transformation, but also because cubic $8 Y S Z$ presents the optimum for ionic conductivity. In Fig. 5 we compare the Raman spectra obtained on machined and nonmachined areas. The lateral resolution of the Raman experiments was $4 \mu \mathrm{m}$ and the depth of the explored area was about $20 \mu \mathrm{m}$. The spectra in the laser processed and unprocessed areas were identical and correspond to the Raman spectra of fully cubic YSZ. The laser ablation process used to machine the plates does not produce significant heating of the ceramic and consequently does not induce phase transformations.

Impedance spectroscopy experiments of the plate using platinum paste electrodes were also carried out. From the EIS experiments at room temperature we obtained the effective capacity of the plate at $10^{4} \mathrm{~Hz}$, which is contributed mainly by the bulk dielectric constant. By comparing this value with that of the unprocessed plate we obtained an effective thickness of the laser machined zones of $47.4 \mu \mathrm{m}$, which coincides with the optical profilometry results. Moreover, this experiment confirmed the absence of perforations in the plate that would lead to a cell short circuit. The electrolyte resistance as a function of the temperature was obtained from the impedance diagrams, which allows the separation of the electrode contribution that is predominant in the low temperature regime. The electrolyte resistance is dominated by conduction across the grain interior, with some contribution from grain boundaries, similar in both the non-machined and laser-machined plates. The ASR values for the laser machined and unprocessed plates are shown in Fig. 6. Laser processing decreased the ASR by a factor of 2.8 , very close to the factor of 3 obtained from optical profilometry and electric capacity estimations. Moreover, we have not observed resistive effects associated with the debris of the laser ablation process that is deposited over the plate surface or to any other transformation in the YSZ original material.

Cell prepared using laser machined electrolytes.-To test the performance of the laser machined plates in real conditions, membrane electrode assemblies (MEA) were prepared using Ni-YSZ and

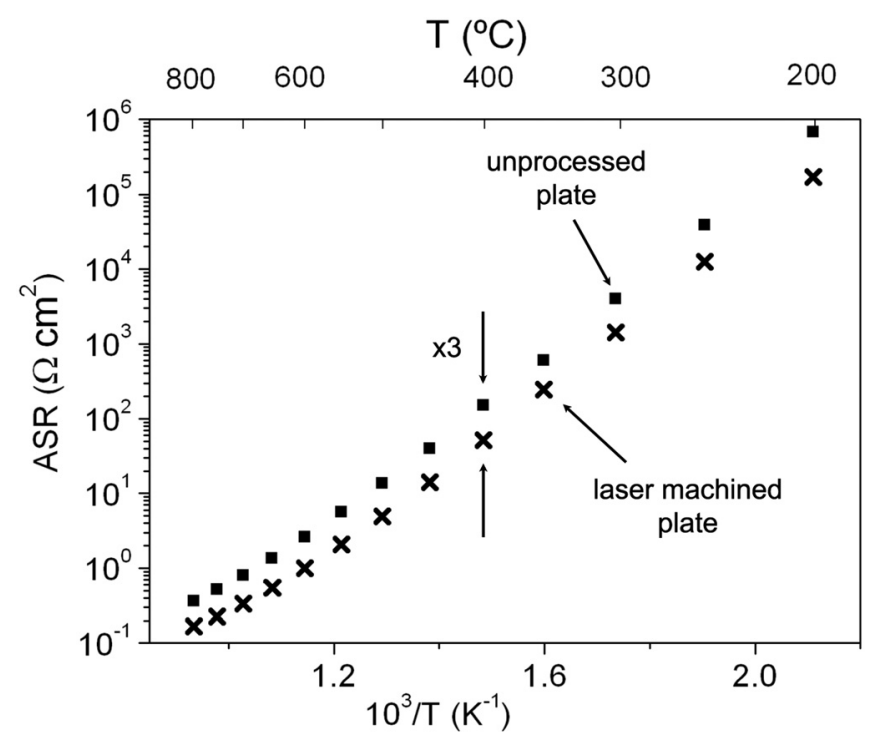

Figure 6. Area Specific Resistance (ASR) as a function of temperature for the unprocessed (squares) and laser machined (crosses) YSZ plate.

LSM-YSZ electrodes. $j$-V measurements are shown in Fig. 7 for a cell using a laser machined electrode with an average thickness of about $50 \mu \mathrm{m}(\mathrm{LM})$ and blank sample using a non-machined electrode (NM, $150 \mu \mathrm{m}$ in thickness) for comparison. Results for

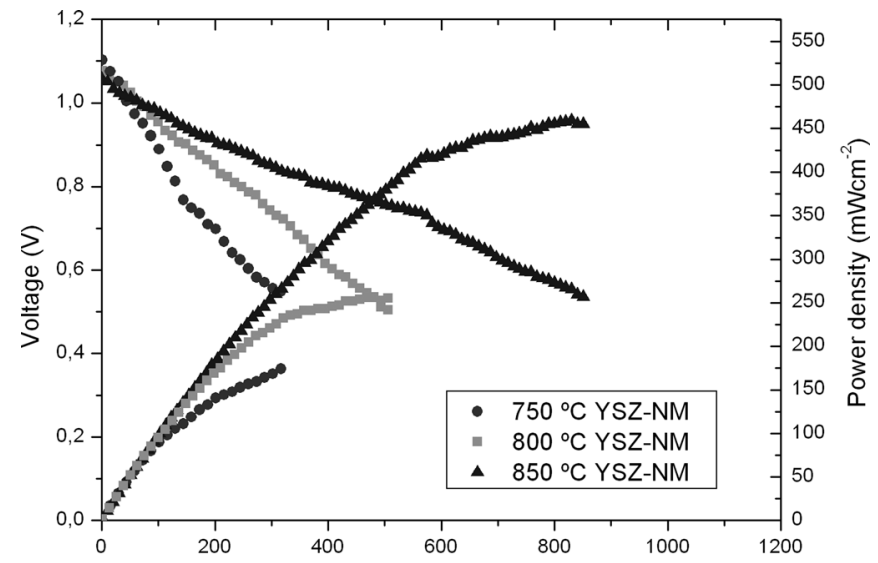

(a)

Current density $\left(\mathrm{Acm}^{-2}\right)$

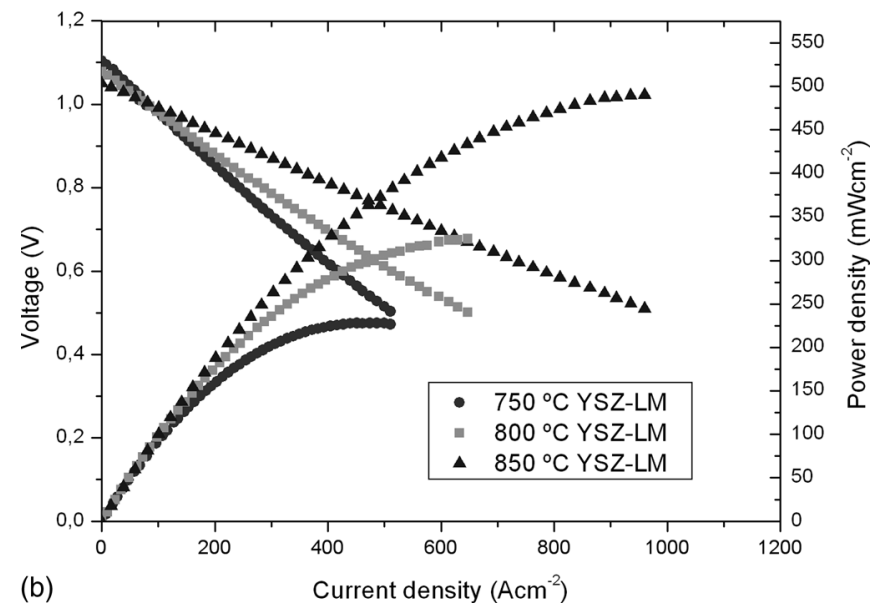

Figure 7. $j$-V curves for various temperatures measured in MEA's prepared with an unprocessed plate (top) and a laser machined YSZ plate (bottom). 


\begin{tabular}{|c|c|c|c|c|c|c|}
\hline $\mathrm{T}\left({ }^{\circ} \mathrm{C}\right)$ & $\begin{array}{l}\text { ASR NM } \\
\left(\Omega \cdot \mathrm{cm}^{2}\right)\end{array}$ & $\begin{array}{l}\text { ASR LM } \\
\left(\Omega \cdot \mathrm{cm}^{2}\right)\end{array}$ & $\begin{array}{c}\mathrm{P} \text { at } 0.7 \mathrm{~V} \mathrm{NM} \\
\left(\mathrm{mW} \cdot \mathrm{cm}^{-2}\right)\end{array}$ & $\begin{array}{c}\text { P at } 0.7 \mathrm{~V} \mathrm{LM} \\
\left(\mathrm{mW} \cdot \mathrm{cm}^{-2}\right)\end{array}$ & $\begin{array}{c}\mathrm{P} \text { at } 0.55 \mathrm{~V} \mathrm{NM} \\
\left(\mathrm{mW} \cdot \mathrm{cm}^{-2}\right)\end{array}$ & $\begin{array}{c}\mathrm{P} \text { at } 0.55 \mathrm{~V} \mathrm{LM} \\
\left(\mathrm{mW} \cdot \mathrm{cm}^{-2}\right)\end{array}$ \\
\hline 800 & 1.06 & 0.90 & 235 & 277 & 254 & 317 \\
\hline 850 & 0.62 & 0.51 & 418 & 431 & 459 & 485 \\
\hline
\end{tabular}

$\mathrm{ASR}_{\text {cell }}$ (average slope from OCV to $0.55 \mathrm{~V}$ ) and power densities of the cell are also summarized in Table I. It can be seen that the $\mathrm{ASR}_{\text {cell }}$ of the machined sample is smaller than the $\mathrm{ASR}_{\text {cell }}$ of the blank sample. Laser thinning of the electrolyte produces a decrease in the cell resistance at $800^{\circ} \mathrm{C}$ of 0.16 and $0.38 \Omega \cdot \mathrm{cm}^{2}$ at $750^{\circ} \mathrm{C}$, which roughly coincide with the resistance of one electrolyte with thickness equal to the difference between blank and machined samples, namely 0.20 and $0.29 \Omega \cdot \mathrm{cm}^{2}$ at 800 and $750^{\circ} \mathrm{C}$ respectively, taken from the data given in Fig. 6. Consequently, the power densities also increase. For the blank sample we have measured power densities at $850^{\circ} \mathrm{C}$ of 418 and $459 \mathrm{mWcm}^{-2}$ at 0.7 and $0.55 \mathrm{~V}$ respectively. Those values are comparable with similar YSZ supported cells ${ }^{20,21}$ although slightly lower due to the use of non-optimized electrodes in our case. For the machined sample, power densities at the same temperature were slightly improved up to 431 and 485 $\mathrm{mWcm}^{-2}$ at 0.7 and $0.55 \mathrm{~V}$ respectively. However, the cell power densities at $750^{\circ} \mathrm{C}$ and $0.7 \mathrm{~V}$ increase by a factor of more than $50 \%$. We have found that at lower operation temperatures the improvement obtained using laser-machined electrolytes is higher in comparison with high temperatures. This fact is associated with the low ionic conductivity of $8 \mathrm{YSZ}$ at $750^{\circ} \mathrm{C}$ and thus, although the LSM-YSZ cathode is not appropriate for low temperature operation, the decrease of the electrolyte resistance after the laser thinning is much more important.

As commented before, our main objective in the future is to reduce the operation temperature of the cell. As expected, there is a clear improvement in terms of cell performance when reducing the thickness of the electrolyte. For this reason further experiments including the use of low temperature cathodes and, especially, the fabrication of a cell with a homogeneous average electrolyte thickness of $\sim 20 \mu \mathrm{m}$ are under way.

\section{Conclusions}

A new method of producing self-supporting thin YSZ membranes by laser machining has been developed. We use a galvanometric controlled laser beam to machine the surface of a conventional YSZ plate by getting thin areas up to $10 \mu \mathrm{m}$ thick, but also maintaining thicker support beams of the same original material to ensure the structural strength of the membrane. The outer areas are left unaltered to facilitate the sealing of the cell. As the final piece is obtained from an original YSZ plate, all parts present the same TEC and do not show the problems of cracking due to thermal cycles presented by thin free-standing electrolyte membranes deposited over $\mathrm{Si}$ or other different supports. In this way, using the laser, we can perform different patterns, as for instance the honeycomb-type structure presented in this paper, but any other configuration is also possible. Currently we have fabricated membranes with an average thickness of about $50 \mu \mathrm{m}$, one third of the original thickness of the plate, and about $0.5 \mathrm{~cm}^{2}$ in surface. However, this method could produce large membranes of 10-20 $\mu \mathrm{m}$ in thickness after optimization. For comparison, applying the ASR $<0.15 \Omega \mathrm{cm}^{2}$ criterion for the electrolyte and considering ideal electrodes, a $150 \mu \mathrm{m}$ thick plate would operate at about $850^{\circ} \mathrm{C}$. After laser machining we could currently get plates with an effective thickness of about $50 \mu \mathrm{m}$, and as a consequence get the same ASR for the electrolyte, and hopefully SOFC power, at about $730^{\circ} \mathrm{C}$. Our final objective is to reduce the effective thickness of the membranes to $20 \mu \mathrm{m}$, and this would imply a reduction in the operation temperature to about $650^{\circ} \mathrm{C}$. The type of laser used in these experiments is relatively low-cost, about $60.000 €$, and currently used in a lot of companies world wide in their production lines. So the laser machining modification studied in this paper is relatively inexpensive at industrial level and could be applied to other electrolytes besides YSZ.

\section{Acknowledgments}

We would like to thank grants MAT2009-14324-C02-01, financed by the Spanish Government (Ministerio de Ciencia e Innovación) and Feder program of the European Community, and GALC-2009/09, financed by the Aragón Government and La Caixa Foundation, for funding the project. The use of Servicio de Microscopia Electrónica (University of Zaragoza) is also acknowledged.

\section{References}

1. N. Q. Minh, J. Am. Ceram. Soc. 76, 563 (1992).

2. B. C. H. Steele and A. Heinzel, Nature (London), 414, 345 (2001).

3. E. C. Subbarao, in Advances in Ceramics, Vol. 3, A. H. Heuer and L. W. Hobbs, Editors, The American Ceramic Society Columbus, Ohio (1981).

4. S. C. Singhal and K. Kendall, High Temperature Solid Oxide Fuel Cells. Fundamentals, Design and Applications, Elsevier, Oxford (2003).

5. C. C. Appel, N. Bonanos, A. Horsewell, and S. Linderoth, J. Mater. Sci., 36, 4493 (2001).

6. P. Bruschi, A. Diligente, A. Nannini, and M. Piotto, Thin Solid Films, 346, 251 (1991).

7. C. D. Baertsch, K. F. Jensen, J. L. Hertz, H. L. Tuller, S. T. Vengallotore, S. M. Spearing, and M. A. Schmidt, J. Mater Res., 19, 2604 (2004).

8. S. J. Berkowitz, A. S. Hirarara, K. Char, and E. N. Grossman, App. Phys. Lett., 69, 2125 (1996).

9. M. M. Seabaugh, M. J. Day, M. G. Beachy, B. McCormick, and S. Ibanez, in Solid Oxide Fuel Cells 11, S. C. Singhal and H. Yokokawa, Editors, PV 25, p. 619, The Electrochemical Society Proceedings Series, Pennington NJ (2009).

10. L. J. Bonderer, P. W. Chen, P. Kocher, and L. J. Gauckler, J. Am. Ceram. Soc., 93, 3624 (2010).

11. A. Larrea, D. Sola, J. I. Peña, R. I Merino, and V. M. Orera, Pat. Appl. Publ., PCT/ ES2010/070750.

12. J. Gurauskis, D. Sola, J. I. Peña, and V. M. Orera, J. Eur. Ceram. Soc. 28, 2673 (2008).

13. D. Sola, J. Gurauskis, J. I. Peña, and V. M. Orera, Mater. Res. Bull. 44, 1910 (2009).

14. D. Sola, A. Escartin, R. Cases, and J. I. Peña, Appl. Surf. Sci., 257, 5413 (2011).

15. D. Baüerle, Laser Processing and Chemistry, p. 693, Springer-Verlag, Berlin (2000).

16. S. J. Skinner and M. A. Laguna-Bercero, Advanced Inorganic Materials for Solid Oxide Fuel Cells in Energy Materials, Duncan W. Bruce, R. Walton, and D. O'Hare, Editors, p. 35, Wiley-VCH Verlag GmbH \& Co. KGaA, Weinheim (2011).

17. M. Ishigame and T. Sakurai, J. Am. Ceram. Soc., 60, 367 (1977).

18. N. R. Harlan, R. I. Merino, J. I. Peña, A. Larrea, V. M. Orera, C. González, P. Poza, and J. Llorca, J. Am. Ceram. Soc., 85, 2025 (2002).

19. M. Yasima, K. Ohtake, M. Kakihana, H. Arashi, and M. Yoshimura, J. Phys Chem. Solids, 57, 17 (1996).

20. Q. X. Fu, F. Tietz, and D. Stöver, J. Electrochem. Soc. 153, 743 (2006).

21. S. Mosch, N. Trofimenko, M. Kusnezoff, T. Betz, and M. Kellner, ECS Trans., 7(1), 381 (2007). 